\title{
Investigational drugs with dual activity against HBV and HIV (Review)
}

\author{
SHIYU SUN ${ }^{1-4}$, QING YANG ${ }^{1-4}$, YUNJIAN SHENG ${ }^{1-4}$, \\ $\mathrm{YI} \mathrm{FU}^{4,5}, \mathrm{CHANGFENG} \mathrm{SUN}{ }^{1-4}$ and CUNLIANG DENG ${ }^{1-3}$

\begin{abstract}
Departments of ${ }^{1}$ Infectious Diseases and ${ }^{2}$ Tuberculosis, ${ }^{3}$ Infection and Immunity Laboratory, Department of Infectious Diseases, The Affiliated Hospital of Southwest Medical University; ${ }^{4}$ School of Clinical Medicine, Southwest Medical University; ${ }^{5}$ Department of Gastrointestinal Surgery,

The Affiliated Hospital of Southwest Medical University, Luzhou, Sichuan 646000, P.R. China
\end{abstract}

Received June 17, 2020; Accepted October 14, 2020

DOI: $10.3892 /$ etm.2020.9467

\begin{abstract}
Chronic hepatitis $\mathrm{B}$ (CHB) and acquired immunodeficiency syndrome (AIDS) are global public health problems that pose a significant health burden. Human immunodeficiency virus (HIV) and hepatitis B virus (HBV) coinfection is common, as these viruses have similar transmission routes, such as blood transmission, sexual transmission and mother-to-child transmission. Coinfection frequently leads to accelerated disease progression. For individuals coinfected with $\mathrm{HIV} / \mathrm{HBV}$, combination antiretroviral therapy containing dual anti-HBV drugs is recommended. Certain studies have also indicated the benefits of antiretroviral drugs with anti-HBV activity in patients with coinfection. A total of four Food and Drug Administration-approved HIV drugs also have anti-HBV activity; namely, emtricitabine, lamivudine, tenofovir disoproxil fumarate and tenofovir alafenamide, which
\end{abstract}

Correspondence to: Dr Changfeng Sun or Professor Cunliang Deng, Department of Infectious Diseases, The Affiliated Hospital of Southwest Medical University, 25 Taiping, Luzhou, Sichuan 646000, P.R. China

E-mail: sun_cf88@swmu.edu.cn

E-mail: dengcunl@swmu.edu.cn

Abbreviations: HBV, hepatitis B virus; AIDS, acquired immunodeficiency syndrome; HAART, highly active antiretroviral therapy; TFV, tenofovir; TDF, tenofovir disoproxil fumarate; TAF, tenofovir alafenamide; cART, combination ART; TLR-7, Toll-like receptor-7; PBMCs, peripheral blood mononuclear cells; NAs, nucleos(t)ide analogues; HCC, hepatocellular carcinoma; SIV, simian immunodeficiency virus; NK, natural killer; CYPs, cyclophilins; MMF, Mycophenolate mofetil; IMPDH, inosine monophosphate dehydrogenase; MPA, mycophenolic acid; dGTP, deoxyguanosine triphosphate; PD-1, programmed cell death receptor 1; PD-L1, programmed cell death ligand 1; NRTIs, nucleoside/nucleotide reverse transcriptase inhibitors; TXL, tenofovir exalidex; HDP-TFV, Hexadecyloxypropyl-tenofovir

Key words: HIV, hepatitis B virus, coinfection, antiviral, dual activity drug, review are all nucleoside reverse transcriptase inhibitors. However, various issues, including drug resistance and side effects, limit their application. Therefore, it is necessary to develop more drugs with dual activity against HBV and HIV. The present review outlines the mechanisms, safety and efficacy of certain drugs that have been investigated for this purpose.
Contents
1. Introduction
2. Immunomodulators
3. Monoclonal antibodies
4. Nucleoside/nucleotide reverse transcriptase inhibitors
5. Cyclophilins inhibitors
6. Conclusions

\section{Introduction}

Chronic hepatitis B (CHB) and acquired immunodeficiency syndrome (AIDS) are both serious public health problems and caused by viruses that have the same transmission paths, including mother-to-child, blood (including minor wounds of the skin and mucous membranes) and sexual contact. Due to their shared transmission routes, coinfections of hepatitis $\mathrm{B}$ virus (HBV) and HIV are common and $\sim 5-20 \%$ of patients living with HIV infection worldwide are also infected with HBV (1). Compared with patients infected with only HBV, $\mathrm{HIV} / \mathrm{HBV}$-coinfected patients have a higher risk of developing end-stage liver disease and an overall higher mortality rate (2-4). Furthermore, the presence of HBV in HIV-positive patients is associated with a lower number of $\mathrm{CD}^{+}$lymphocytes and a lower virologic response against HIV during treatment (5).

It is necessary for coinfected patients to start antiviral treatment as early as possible because as the degree of immunodeficiency worsens, the patient's response to HBV treatment regimens is reduced (6). Highly active antiretroviral therapy (HAART) is able to effectively promote immune system reconstitution (7). The World Health Organization (WHO) 
recommends that patients living with HIV who are coinfected with HBV with severe chronic liver disease are required to initiate ART regardless of their WHO clinical stage and CD4 ${ }^{+}$ cell count (8) and Chinese guidelines also suggest that they need to start HAART if coinfected with HBV regardless of their $\mathrm{CD}^{+}$cell count as early as possible (9). However, immune reconstitution syndrome secondary to HAART may cause hepatitis flares; therefore, HBV and HIV should be treated at the same time (7). Using one drug that is active against $\mathrm{HBV}$ is able to induce $\mathrm{HIV}$ resistance to nucleoside drugs; therefore, two anti-HBV drugs should be included in the treatment plan. For HIV/HBV coinfected individuals, combination ART (cART) with dual anti-HBV and anti-HIV antiretroviral activity is recommended (10). The treatment goals are to control HIV and HBV transmission, suppress viral replication and prevent drug resistance mutations in reverse transcriptase (4). The treatment duration for $\mathrm{HBV}$ in coinfected patients is indefinite due to the low response rates and the requirement for lifelong treatment for HIV (11). Thus, the drugs should be selected carefully and closely monitored during treatment to minimize the risk of HBV and HIV drug resistance.

Numerous studies have proven the importance of dual activity drugs for coinfection treatment. Using highly effective cART with dual activity is able to significantly reduce the risk of developing end-stage liver disease in HIV/HBV coinfected patients (12). Interruption of HIV medications with anti-HBV activity in HIV/HBV coinfected individuals may result in HBV reactivation and/or hepatitis (13). HIV mono-infected patients may be protected from HBV infection by using anti-HBV antiretroviral medications (14). However, only four Food and Drug Administration (FDA)-approved HIV drugs that have anti-HBV activity have been developed thus far, namely emtricitabine, lamivudine, tenofovir (TFV) disoproxil fumarate (TDF) and TFV alafenamide (TAF), all of which are nucleoside reverse transcriptase inhibitors (15). In a meta-analysis, the evidence for the relative effectiveness of these drugs in the treatment of HBV/HIV coinfection was insufficient (3). Considering the drug resistance of HBV and HIV and the side effects of the medications, the development of novel drugs with dual activity is urgent to ensure that there is a sufficient number of alternative drugs for treating HIV/HBV coinfection. Fortunately, antiretroviral drugs with dual activity for treating HBV and/or HIV are under different pre-clinical or clinical study stage. In the present review, the mechanisms, safety and effectiveness of drugs investigated for HIV/HBV coinfection are provided.

\section{Immunomodulators}

GS-9620. Toll-like receptor-7 (TLR-7) has a vital role in the innate immune response against pathogens. GS-9620, also called vesatolimod, was developed by Gilead and is a potent, selective and orally active small-molecule agonist of TLR-7. GS-9620 is able to activate T cells and natural killer (NK) cells, inducing immune activation. Furthermore, GS-9620 is capable of increasing the plasma levels of various cytokines and the expression levels of associated genes, such as IFN $\alpha$ and IFN-stimulated genes (16). CHB is characterized by persistently low innate and adaptive immune responses.
Therefore, the TLR7 agonist GS-9620 may have the potential for improving anti-HBV immunity. Certain studies have indicated that GS-9620 is able to sustainably suppress viral DNA and antigens in the sera of woodchuck and chimpanzee models of CHB $(17,18)$. The mean maximum reduction in viral DNA was $2.2 \log$ s and reductions of $>1 \log$ persisted for months in HBV-infected chimpanzees treated with GS-9620 (18). In another study, GS-9620 reduced the levels of HBV DNA, RNA and antigens in vitro in HBV infection models (19). Furthermore, GS-9620 administration reduced covalently closed circular (ccc)DNA levels and the incidence of hepatocellular carcinoma (HCC) in woodchucks with chronic woodchuck hepatitis virus infection (17). Clinical research on GS-9620 in patients with CHB is preliminary. Oral administration of GS-9620 at 1-, 2- or 4-mg doses did not cause any significant decrease in hepatitis B surface antigen ( $\mathrm{HBsAg})$ in patients with $\mathrm{CHB}$ who were not taking any oral antivirals or who were virally suppressed by oral antiviral treatment, which may be due to differences in dose administration and/or concentration and species-specific effects of the therapy in the animal and human CHB models. However, GS-9620 has been indicated to be safe and well-tolerated in patients with CHB (20-22).

HIV-1 infection remains incurable due to a persistent viral reservoir, requiring the administration of antiretroviral drugs throughout life. Long-lived memory $\mathrm{CD}^{+} \mathrm{T}$ cells serve as the primary reservoir of latent HIV. Interrupted HIV treatment may result in viral reactivation. The latent reservoir in resting $\mathrm{CD}^{+} \mathrm{T}$ cells is considered to be the major obstacle to HIV treatment. Toll-like receptor agonists are able to reverse HIV-1 latency (23), induce latent HIV expression and promote the immune system to recognize and eliminate infected cells. Tsai et al (24) and Sloan et al (25) indicated that GS-9620 has the ability to activate HIV expression ex vivo in peripheral blood mononuclear cells (PBMCs) isolated from HIV-infected patients with suppressive cART. Furthermore, GS-9620 is capable of augmenting the ability to kill HIV-infected cells through enhanced HIV-specific cellular cytotoxicity and anti-HIV antibody-mediated immunity. Treatment of PBMCs with GS-9620 induced a concentration-dependent increase in HIV-specific $\mathrm{CD}^{+}$ T-cell activation (26). In addition, treatment with GS-9620 significantly reduced the viral reservoir in simian immunodeficiency virus (SIV)-infected rhesus monkeys (27). Borducchi et al (28) reported that the V3 glycan-dependent broadly neutralizing antibody, PGT121, combined with GS-9620 delayed viral rebound following ART discontinuation in simian HIV-infected monkeys. Of note, no serious adverse events were observed in virologically suppressed HIV-1-infected adults when the doses of GS-9620 were increased in a phase 1b study (29). Overall, GS-9620 may be a candidate drug with dual effects caused by the regulation or activation of innate and adaptive immunity.

$I F N$. IFNs have potent antiviral effects. They exert antiviral activity by regulating the immune response and upregulating the expression of antiviral genes. IFN $\alpha$ is an FDA-approved medicine currently used to treat HBV and HCV infections due to its robust antiviral activity. Pegylated IFN, usually called Peg-IFN, is a chemically modified form of standard IFN. 
Compared with standard IFN, Peg-IFN has a longer half-life and stays in the body for a longer duration. Peg-IFN $\alpha$ is available in two forms, peg-IFN $\alpha-2 \mathrm{a}$ and-2b, with the commercial names Pegasys and PegIntron, respectively.

Compared with that of nucleos(t)ide analogs (NAs), treatment with Peg-IFN $\alpha$ has the advantages of limited treatment duration, a higher rate of $\mathrm{HBeAg}$ and $\mathrm{HBsAg}$ seroconversion, a higher chance of sustained off-treatment virological response and lack of resistance. Furthermore, treatment with Peg-IFN $\alpha$ has a lower HBV-associated HCC incidence than NAs in HBV-infected patients (30). However, Peg-IFN $\alpha$ has been associated with severe adverse events, has low efficacy of viral suppression and is administered by subcutaneous injection, which are disadvantages. IFN therapy is contraindicated in patients with decompensated cirrhosis, pregnancy, heart failure, chronic obstructive pulmonary disease and psychosis. Thus, pegylated IFN must be carefully selected according to the patient's condition.

Furthermore, IFNs have anti-HIV activity (31-39). According to Frissen et al (37), high-dose IFN $\alpha-2 \mathrm{a}$ had potent anti-HIV activity. Asmuth et al (35) reported that pegylated IFN $\alpha-2$ a treatment reduced the viral load in untreated HIV-infected patients without HCV infection. Pegylated IFN $\alpha-2 \mathrm{a}$ is also useful in patients with multiple resistance-associated mutations and who are resistant to most antiretroviral medications (40). Furthermore, several studies suggested that treatment with IFN $\alpha$ may diminish the HIV reservoir size (31-33). However, the effect of IFN on HIV remains controversial due to potential deleterious effects during later stages of HIV infection. Sandler et al (41) suggested that continuous IFN $\alpha$-2a therapy may lead to IFN desensitization and antiviral gene downregulation, thereby increasing the SIV reservoir size and accelerating CD4 cell depletion. IFN $\alpha$ levels were positively correlated with viral load and negatively correlated with the $\mathrm{CD}^{+} \mathrm{T}$-cell count in chronic HIV infection $(42,43)$. Cheng et al (44) confirmed that blocking the sustained elevations in IFN-I signaling enhanced immune recovery and reduced HIV-1 reservoirs. However, another study indicated that the reduction in $\mathrm{CD}^{+}$ cells may be due to the HIV-infected cells being more vulnerable to IFN $\alpha$-mediated attacks, resulting in a decrease in HIV DNA (39).

In summary, the interaction between HIV and type I IFNs is complex and the effects of IFNs on HIV remain uncertain; however, they may still be part of an effective strategy for eradicating the virus. The concentration and regimen of IFN should be carefully selected to ensure that they trigger the appropriate antiviral response. Thus, the benefit of IFN treatment outcomes may depend on the stage of HIV infection and the patient's immune status.

IL-15. IL-15, a 14 - to $15-\mathrm{kDa}$ cytokine, is able to eliminate viruses in infected cells by enhancing innate and adaptive immunity through inducing the activation and proliferation of $\mathrm{T}$ and NK cells. Among HIV-infected patients who have received structured treatment interruption (STI), HIV replication control was associated with sustained IL-15 levels (45). IL-15 has been proven to attenuate the impairment of NK cells in chronic HBV carriers (46). IL-15 therapy is also able to augment NK-cell function in virus-suppressed HIV-positive individuals on ART, and IL-15-stimulated NK cells may eliminate latently HIV-infected cells exposed to the histone deacetylase inhibitor vorinostat (a latency reversal agent) (47). IL-15 and ALT-803 (an IL-15 superagonist, also known as $\mathrm{N}-803$ ) drove virus transcripts in latently infected CD4 $\mathrm{T}$ cells in vitro to be recognized by autologous HIV-specific CD8 T-cells, suggesting their roles as latency-reversing agents (48). In ART-suppressed, SIV-infected macaques and HIV-infected humanized mice, ALT-803 combined with CD8 lymphocyte depletion induced a sustained and robust reversal of latency (49). Another study suggested that the administration of ALT-803 temporarily inhibited viral replication in SIV-infected animals without ART (50). Walter et al (51) revealed that high levels of IL-15 in breast milk prevented postnatal HIV transmission. In addition, IL-15 has potential as an immune adjuvant. Coadministration of HIV vaccine vectors and vaccinia viruses expressing IL-15 contributed to the robust $\mathrm{CD} 8^{+} \mathrm{T}$-cell responses (52). However, IL-15 may have a deleterious role in HIV infection, particularly in the acute phase. IL-15 is able to increase the viral set point and accelerate disease progression (53). It abrogated the decrease in viral load induced by vaccines in SIV-infected macaques (54). IL-15 was significantly associated with HIV viremia and negatively correlated with the CD4+ cell count in HIV-1 infected patients with viral loads of $>100,000$ copies $/ \mathrm{ml}$, which was associated with IL-15-induced immune activation (55). In addition, IL-15 may cause tissue damage due to its strong proinflammatory properties and T cell-mediated alveolitis induced by IL-15 has been confirmed in patients with AIDS (56).

Only a small number of studies have demonstrated the inhibitory effect of IL-15 on HBV replication $(57,58)$. In IL-15-treated HBV transgenic mice, reduced viral loads in the serum and undetectable HBV DNA intermediates in the liver were observed (58). Hydrodynamically injecting the plasmid pLIVE-IL-15, which expresses IL-15, into C57BL/6 mice reduced serum $\mathrm{HBsAg}$ and hepatitis $\mathrm{B}$ e antigen $(\mathrm{HBeAg})$ titers and liver HBV DNA levels in an IFN- $\beta$-dependent manner (57). According to the results of certain studies $(57,58)$, IL-15 may have therapeutic potential to inhibit HBV replication in vivo, but sufficient evidence supporting its effectiveness in humans is lacking.

Mycophenolate mofetil (MMF). MMF is an immunosuppressant that may be used as a prodrug of the active metabolite of mycophenolic acid to increase the bioavailability of mycophenolic acid. MMF is able to selectively and reversibly inhibit the type II isoform of inosine monophosphate dehydrogenase (IMPDH) in T and B lymphocytes and block the conversion of inosine monophosphate to guanosine monophosphate in the de novo synthetic pathway of the guanine purine (59). MMF is hydrolyzed to mycophenolic acid (MPA) in vivo and these two compounds have the same immune activity. Suppressing IMPDH in lymphocytes may cause guanosine triphosphate (GTP) and deoxyGTP (dGTP) depletion (60). Furthermore, inhibition of IMPDH activity may block T-lymphocyte proliferation (61) and increase the apoptosis rate of activated $\mathrm{T}$ lymphocytes (62). MMF exerts cytostatic effects and potential antiviral effects by depleting GTP and dGTP pools (63), and RNA and DNA synthesis require GTP or dGTP as substrates (64). MMF may be used as an adjuvant 
for HIV-1 infection treatment and exerts an anti-HIV effect through the following three mechanisms: i) Depletion of substrates required for reverse transcriptase; ii) depletion of the activated $\mathrm{CD} 4^{+} \mathrm{T}$-lymphocyte pools and limitation of the availability of HIV-targeted cells (60); and iii) inhibition of syncytium formation by reducing the amount of gp120, which is a glycoprotein protruding from the outer surface of the HIV virion that has a molecular weight of 120 (64).

Numerous studies have demonstrated that MMF has activity against HIV in vivo and in vitro $(63,65-69)$. Treatment of patients with acute HIV-1 infection with antiretroviral therapy (comprised of 5 drugs) combined with MMF (2 g/d) decreased the HIV-1 RNA load significantly and rendered HIV-1 antibody undetectable, but the RNA load rebounded when the treatment was stopped (70). In addition, adding MMF to HAART for HIV-1-infected patients reduced the number of latently infected CD4 ${ }^{+} \mathrm{T}$ cells (69). A phase II study (NCT03262441) to determine whether administering MMF treatment for $>22$ months is able to reduce the reservoirs is currently ongoing. García et al (63) indicated that the combination of MMF with HAART delayed viral load rebound and MMF alone enhanced the control of viral replication when lymphocyte proliferation was suppressed. Furthermore, MMF is able to improve the activity of antiretroviral drugs in a dose-dependent manner $(67,71,72)$. Coadministration of abacavir (a guanosine analog inhibitor) and MPA enhanced the anti-HIV effect of abacavir in both stimulated PBMC and monocyte-derived macrophages (60) and reduced the plasma levels of HIV RNA (73).

Similarly, MMF/MPA is able to theoretically inhibit HBV replication. MPA at a concentration of $10 \mu \mathrm{g} / \mathrm{ml}$ reduced the secretion of HBsAg and HBV DNA without inducing cytotoxicity, and HBV cccDNA and mRNA were undetectable (74). It is safe to use lamivudine and MMF prophylactically in renal transplant recipients with $\mathrm{CHB}$ who did not receive any antiviral therapy prior to transplantation (75). In a mouse model with hydrodynamic injection, MMF reduced the serum HBsAg and HBV DNA levels (76). In another study, MPA inhibited HBsAg and HBeAg expression, as well as HBV DNA replication in vitro in a dose-dependent manner (77). Furthermore, MMF enhanced the anti-HBV activity of guanine- and diaminopurine-based nucleos(t)ide analogs such as lobucavir and entecavir, probably by reducing the competing natural substrate dGTP $(78,79)$. Thus, MMF appears to have an inhibitory effect on HBV replication. However, in certain studies, this inhibitory activity was not detected. MMF has the ability to inhibit hepatic NK-cell proliferation and activity in vivo, where NK cells have a critical role in the defense against $\mathrm{HBV}$ infection. A study suggested that MMF was not beneficial in suppressing HBV replication after liver transplantation in lamivudine-resistant patients (80). Treatment with MMF alone may stimulate virus replication with glomerulonephritis in patients who are HBV carriers but had not received antiviral treatment (81). Pyrimidine synthesis inhibitor (leflunomide, FK778) and MPA increased the risk of HBV replication in cell culture models (82). In summary, MPA may both inhibit and stimulate the proliferation of HBV. Based on this contradictory phenomenon, Pan et al (83) evaluated the effects of MPA in HepG2.2.15 cells and indicated that a low dose $(1 \mu \mathrm{g} / \mathrm{ml})$ of MPA increased the HBV titers, while a high dose (5 and $10 \mu \mathrm{g} / \mathrm{ml}$ ) of MPA decreased HBV titers. However, all three doses of MPA significantly increased HBsAg expression, which was consistent with previous results (84); thus, it may be assumed that MPA has proviral effects.

MMF appears to be safe and the common side effects of MMF are usually mild (85). MMF, as an immunosuppressant, has not been approved for treating HIV or HBV infection, as the evidence is insufficient. More clinical trials are required to confirm its antiviral activity. However, it is still expected to become an adjuvant treatment for HIV.

\section{Monoclonal antibodies}

Cemiplimab. Programmed cell death receptor 1 (PD-1) is an immune checkpoint molecule that is necessary to maintain immune homeostasis upon binding to its ligands, programmed cell death ligand 1 (PD-L1) and ligand 2 (PD-L2). The PD-1/PD-L1 axis has a crucial role in viral infection and is upregulated in $\mathrm{CHB}$ and chronic HIV infections, where it may maintain chronic infection by attenuating the antiviral immune responses mediated by $\mathrm{T}$ cells or NK cells $(86,87)$. PD-1 is intensely and extensively expressed during chronic infection. As mentioned above, even after receiving long-term cART, the latent reservoir in HIV-positive patients remains in resting $\mathrm{CD}^{+}$cells expressing PD-1 (88). By establishing an HIV latency model in vitro, Evans et al (89) demonstrated that PD- $1^{\text {high }} \mathrm{CD} 4^{+}$memory $\mathrm{T}$ cells had high levels of latency and that blocking PD-1 prior to infection reduced the incidence of latency, suggesting that PD-1 may help to establish and maintain latent HIV infection. PD-1/PD-L1 blockade enhanced viral-specific T-cell function, increased memory B-cell proliferation $(90,91)$ and restored or enhanced host immune functions. Blocking the PD-1/PD-L1 pathway may contribute to treating chronic infections. Several studies have indicated that blocking PD-1 has an effect on HBV/SIV (92-95) and promotes latency reversal $(89,96)$. In addition, PD-1, as an important immunosuppressive agent, may help to prevent severe liver damage and blocking the PD-1/PD-L1 axis may cause liver cell destruction and HBV reactivation (97). One study demonstrated that during anti-PD-1 treatment, certain patients with resolved HBV infection developed HBV reactivation (98). Therefore, blocking PD-1/PD-L1 may have a certain value in treating $\mathrm{HBV} / \mathrm{HIV}$ infection, but the HBV reactivation risk cannot be ignored.

Cemiplimab (REGN2810) is a high-affinity and hinge-stabilized IgG4 monoclonal antibody against cell surface PD-1 (99), which was developed by Regeneron Pharmaceuticals in collaboration with Sanofi. As previously mentioned, the antiviral effect of certain PD-1/PD-L1 inhibitors has been confirmed in HIV/SIV and HBV models; therefore, it is speculated that cemiplimab may have a similar impact and potential to treat HIV/HBV coinfection. Currently, two phase I/II studies are underway to evaluate the safety and immunotherapeutic activity of cemiplimab in patients infected with HIV-1 or HBV on suppressive antiviral therapy [NCT03787095 (100) and NCT04046107 (101)].

Pembrolizumab. Similar to the above, pembrolizumab (Keytruda) is an IgG4 monoclonal antibody targeted to 
PD-1. A phase I study indicated that pembrolizumab was safe in the treatment of different types of cancer in patients living with HIV and one participant experienced persistent low-level HIV viremia (<400 copies/ml) (102). Patients with metastatic melanoma treated with pembrolizumab remained safe in the context of their HBV infection (103); thus, pembrolizumab may be used to treat $\mathrm{HBV}$ infection in theory. However, a 51-year-old male patient diagnosed with stage IV lung adenocarcinoma developed reactivation of HBV when treated with pembrolizumab (104). A phase I study to detect the safety of a single dose of pembrolizumab in HIV-positive patients without cancer is currently underway (NCT03239899) (105). However, the safety and efficacy of PD-1 inhibitors in HIV/HBV coinfected patients remain uncertain. The evidence is still insufficient to indicate that treating HBV- or HIV-positive patients in the absence of tumors with PD-1/PD-L1 inhibitors is effective, as patients with HBV or HIV infection have traditionally been excluded from clinical trials due to a theoretical risk of immune reconstitution inflammatory syndrome (106). Although a small number of studies $(104,107)$ on PD-1 inhibitors in HBV mono-infection are available, suggesting that they may have a proviral effect, these inhibitors enhance host immune functions and are a promising immunotherapy for HIV/AIDS (108). Targeting the PD1/PD-L1 pathway may be used as a therapeutic strategy to improve immune function and target the viral reservoir (109). Combination therapy may be a more promising treatment strategy. For instance, IL-15 combined with anti-PD-L1 antibody is able to enhance $\mathrm{HIV}$-specific CD8 ${ }^{+}$-cell function (110).

\section{Nucleoside/nucleotide reverse transcriptase inhibitors}

TFV, a nucleotide (nucleoside monophosphate) analogue reverse transcriptase inhibitor, was originally described in 1993 (111) and was approved for clinical use in its oral prodrug form, such as TDF and TAF. TDF was the first selected for clinical development and was ultimately approved by the FDA for the treatment of HIV and HBV in 2001 and 2008, respectively (112). TAF was approved by the FDA in 2016 for treating HBV, which has higher safety than TDF. CMX157, also known as Hexadecyloxypropyl-TFV and TFV exalidex (TXL), is a novel lipid conjugate prodrug of TFV. It is the strategic collaboration project achieved by Contravir and Chemirex in 2014. It is effectively targeted to the liver and has higher antiviral activity and lower toxicity in the bone and kidney than TFV. CMX157 is considered to be an effective drug for treating HBV and HIV infection (113-118). The antiviral activity of CMX157 against HIV and HBV was 260 -fold and 4.5-fold that of TFV in vitro, respectively (116). Furthermore, CMX157 is also effective in nucleoside/nucleotide-resistant HIV (115). In completed clinical trials, CMX157 was indicated to be safe and tolerable in healthy subjects and patients with HBV [NCT01080820 (119), NCT02710604 (120) and NCT02585440 (121)]. However, the agreement between Contravir and Chemirex was terminated in 2019. Whether Chemirex will continue to develop CMX157 is unclear (122). Considering that CMX157 has potent antiviral activity in $\mathrm{HBV}$ and HIV infection and it is still considered to be a promising drug. In view of its strong antiviral activity and low toxicity, it would be beneficial if Chemirex were able continue to develop CMX157.

\section{Cyclophilins inhibitors}

Cyclophilins (CYPs) belong to a protein family with peptidylprolyl isomerase activity; they promote protein folding and have essential roles in various biological processes. Among these proteins, CyPA is critical to HIV-1 and HBV virus replication $(123,124)$. Certain studies indicated that CYP inhibitors interfere with HBV and HIV replication $(125,126)$. CRV431 (formerly CPI-431-32) is a cyclophilin inhibitor that targets CypA and it has been demonstrated to possess broad-spectrum antiviral activity against HIV, HBV, HDV and $\mathrm{HCV}$ by disrupting the interactions between CypA and viral proteins (123). It blocks the interaction between CypA and the HIV-1 capsid to inhibit HIV replication. Furthermore, it also has efficacy against drug-resistant HIV-1 (127).

In addition, CRV431 is able to reduce multiple HBV infection markers, including DNA, HBsAg and HBeAg, by blocking the interaction between HBV X protein or HBsAg and CypA or by inhibiting viral entry, which relies on the vital receptor sodium taurocholate cotransporting polypeptide $(128,129)$. CRV431 reduced the level of serum HBsAg and liver HBV DNA in transgenic mice in a dose-dependent manner, and it was also indicated that low-dose CRV431 (10 mg/kg/d) combined with the TFV prodrug TXL resulted in an additive inhibitory effect (130). A clinical trial to assess the safety, tolerability and pharmacokinetics of CRV431 in patients with CHB is currently ongoing [National Clinical Trial (NCT) identifier no. NCT03596697] (131).

A study demonstrated that CRV431 is metabolized mainly by the cytochrome P450 enzyme (124), while other nucleotide drugs are metabolized predominantly by the kidneys. Therefore, it was speculated that the potential drug-drug interaction between CRV431 and nucleotide drugs may be minimal. To date, CRV431 has demonstrated an excellent safety profile in all animal and clinical studies. Furthermore, CRV431 has antisteatosis, antiinflammatory, antifibrotic and antitumor activities (132). Therefore, CRV431 is a bright prospect in the treatment of liver diseases and serves as a promising drug for the treatment of liver disease and HIV-1 infection.

\section{Conclusions}

At present, there is a large number of $\mathrm{HIV} / \mathrm{HBV}$ coinfected patients worldwide and it continues to increase. Coinfection of HBV and HIV is able to accelerate disease progression and may severely impact the health of patients. At present, it is recommended that coinfected patients use drugs with dual antiviral effects. However, there are several reasons to limit the applications of these drugs. Liver enzyme flares may be caused by drug resistance during HAART. Due to the genetic variability of $\mathrm{HBV}$, certain $\mathrm{HBV}$ genotypes may naturally have lower sensitivity or resistance to certain anti-HBV drugs. For instance, genotype E exhibited a natural resistance to certain $\mathrm{HBV}$ medicines and $\mathrm{HBC}$ has a reduced sensitivity to IFN $\alpha$ (133). In addition, HBV may have cross-resistance to different drugs, such as those caused by lamivudine-induced resistance mutations, after several years of treatment and resistance to emtricitabine, as the two drugs have a similar 
structure (134). Furthermore, treatment choices for HBV infection are limited by drug resistance to HIV. However, drugs with dual activity are able to prevent HBV and HIV reverse-transcriptase resistance mutations associated with drug resistance. In addition, renal function is a factor that requires to be considered when choosing drugs, particularly TDF/TAF, which have limitations for patients with renal insufficiency. Consequently, it is necessary to develop more drugs with dual activity. First, considering the rapid mutation rate of $\mathrm{HBV}$ and the frequent resistance of certain antiviral drugs, novel drugs with dual activity must be developed to address this problem. In addition, novel antiviral drugs may overcome the limitations caused by renal insufficiency and other side effects. Immune dysfunction in patients infected with HBV or HIV rapidly decreases the ability to control viral replication. Therefore, immunomodulators acting on the immune system are promising for the treatment of these two viruses. The potential of NRTIs and monoclonal antibodies for treating HBV and HIV is considerable. However, certain drugs are double-edged swords. Understanding the host's immune status and disease progression is essential for drug management. To date, most of dual-effect drugs are not available to the increasing number of coinfected individuals due to the limitations of drug resistance or toxicity, and the development of dual-activity drugs remains particularly urgent. In the present review, certain dual-activity drugs that are at the laboratory investigation stage were presented, but evidence to support their activity against HBV and HIV is limited and more clinical trials are required to prove the dual activity of these drugs.

\section{Acknowledgements}

Not applicable.

\section{Funding}

This work received financial support from the Scientific Research Project of Sichuan Provincial Health and Family Planning Commission (grant no. 18PJ340), Luzhou Municipal People's Government-Southwest Medical University Science and Technology Strategic Cooperation Applied Basic Research Project (grant no. 2018LZXNYD-ZK29), the Scientific Research Project for Young Researchers of Southwest Medical University (grant no. 2017-ZRQN-103) and the Affiliated Hospital of Southwest Medical University Research Grant (grant no. 16237).

\section{Availability of data and materials}

Not applicable.

\section{Authors' contributions}

CS and CD contributed to the planning and design of the study. SS was responsible for the collection of references and writing of the manuscript. QY, YS and YF contributed to manuscript modification. All authors contributed to drafting the manuscript and interpretation of results. All authors read and approved the final version of the manuscript.

\section{Ethics approval and consent to participate}

Not applicable.

\section{Patient consent for publication}

Not applicable.

\section{Competing interests}

The authors declare that they have no competing interests.

\section{References}

1. Singh KP, Crane M, Audsley J, Avihingsanon A, Sasadeusz J and Lewin SR: HIV-hepatitis B virus coinfection: Epidemiology, pathogenesis, and treatment. AIDS 31: 2035-2052, 2017.

2. Nikolopoulos GK, Paraskevis D, Hatzitheodorou E, Moschidis Z, Sypsa V, Zavitsanos X, Kalapothaki V and Hatzakis A: Impact of hepatitis B virus infection on the progression of AIDS and mortality in HIV-infected individuals: A cohort study and meta-analysis. Clin Infect Dis 48: 1763-1771, 2009.

3. Naing C, Poovorawan Y and Tong K: Comparative effectiveness of anti-viral drugs with dual activity for treating hepatitis $\mathrm{B}$ and HIV co-infected patients: A network meta-analysis. BMC Infect Dis 18: 564, 2018.

4. Levy V and Grant R: Antiretroviral therapy for hepatitis B virus-HIV-coinfected patients: Promises and pitfalls. Clin Infect Dis 43: 904-910, 2006.

5. Sun HY Sheng WH, Tsai MS, Lee KY, Chang SY and Hung CC: Hepatitis B virus coinfection in human immunodeficiency virus-infected patients: A review. World J Gastroenterol 20: 14598-14614, 2014.

6. Núñez M,Puoti M,Camino N and Soriano V: Treatment of chronic hepatitis B in the human immunodeficiency virus-infected patient: Present and future. Clin Infect Dis 37: 1678-1685, 2003.

7. Mendes-Corrêa M and Núñez M: Management of HIV and hepatitis virus coinfection. Expert Opin Pharmacother 11: 2497-2516, 2010.

8. Consolidated guidelines on the use of antiretroviral drugs for treating and preventing HIV infection. World Health Organization [updated June 2013]. https://www.who.int/hiv/pub/guidelines/arv2013/art/WHO_CG_table_7.1.pdf?ua=1. Accessed October 22, 2020

9. AIDS and Hepatitis C Professional Group, Society of Infectious Diseases, Chinese Medical Association; Chinese Center for Disease Control and Prevention: Chinese guidelines for diagnosis and treatment of HIV/AIDS (2018). Zhonghua Nei Ke Za Zhi 57: 867-884, 2018 (In Chinese).

10. Lin JJ, Lin KY, Tang HJ, Lin SP, Lee YC, Liu CE, Huang YS, Wang NC, Li CW, Ko WC, et al: Hepatitis B virus seroprevalence among HIV-infected patients receiving combination antiretroviral therapy three decades after universal neonatal hepatitis B immunization program in Taiwan. J Microbiol Immunol Infect: Oct 30, 2019 (Epub ahead of print). doi: 10.1016/j. jmii.2019.10.005.

11. Lai CL and Yuen MF: Management of chronic hepatitis B in patients from special populations. Cold Spring Harb Perspect Med 5: a021527, 2015

12. Lieveld FI, Smit C, Richter C, van Erpecum KJ, Spanier BWM, Gisolf EH, Vrolijk JM, Siersema PD, Hoepelman AIM, Reiss P and Arends JE: Liver decompensation in HIV/Hepatitis B coinfection in the combination antiretroviral therapy era does not seem increased compared to hepatitis B mono-infection. Liver Int 39: 470-483, 2019.

13. Dore GJ, Soriano V, Rockstroh J, Kupfer B, Tedaldi E, Peters L, Neuhaus J, Puoti M, Klein MB, Mocroft A, et al: Frequent hepatitis B virus rebound among HIV-hepatitis B virus-coinfected patients following antiretroviral therapy interruption. AIDS 24: 857-865, 2010.

14. Shilaih M, Marzel A, Scherrer AU, Braun DL, Kovari H, Rougemont M, Darling K, Battegay M, Hoffmann M, Bernasconi E, et al: Dually Active HIV/HBV antiretrovirals as protection against incident hepatitis B infections: Potential for prophylaxis. J Infect Dis 214: 599-606, 2016. 
15. Soriano V, Barreiro P, Benitez L, Peña JM and de Mendoza C: New antivirals for the treatment of chronic hepatitis B. Expert Opin Investig Drugs 26: 843-851, 2017.

16. Fosdick A, Zheng J, Pflanz S, Frey CR, Hesselgesser J, Halcomb RL, Wolfgang G and Tumas DB: Pharmacokinetic and pharmacodynamic properties of GS-9620, a novel Toll-like receptor 7 agonist, demonstrate interferon-stimulated gene induction without detectable serum interferon at low oral doses. J Pharmacol Exp Ther 348: 96-105, 2014

17. Menne S, Tumas DB, Liu KH, Thampi L, AlDeghaither D, Baldwin BH, Bellezza CA, Cote PJ, Zheng J, Halcomb R, et al: Sustained efficacy and seroconversion with the Toll-like receptor 7 agonist GS-9620 in the Woodchuck model of chronic hepatitis B. J Hepatol 62: 1237-1245, 2015.

18. Lanford RE, Guerra B, Chavez D, Giavedoni L, Hodara VL, Brasky KM, Fosdick A, Frey CR, Zheng J, Wolfgang G, et al: GS-9620, an oral agonist of Toll-like receptor-7, induces prolonged suppression of hepatitis B virus in chronically infected chimpanzees. Gastroenterology 144: 1508-1517, 1517. e1-e10, 2013.

19. Niu C, Li L, Daffis S, Lucifora J, Bonnin M, Maadadi S, Salas E, Chu R, Ramos H, Livingston CM, et al: Toll-like receptor 7 agonist GS-9620 induces prolonged inhibition of HBV via a type interferon-dependent mechanism. J Hepatol 68: 922-931, 2018.

20. Janssen HLA, Brunetto MR, Kim YJ, Ferrari C, Massetto B Nguyen AH, Joshi A, Woo J, Lau AH, Gaggar A, et al: Safety, efficacy and pharmacodynamics of vesatolimod (GS-9620) in virally suppressed patients with chronic hepatitis B. J Hepatol 68: 431-440, 2018

21. Boni C, Vecchi A, Rossi M, Laccabue D, Giuberti T, Alfieri A, Lampertico P, Grossi G, Facchetti F, Brunetto MR, et al: TLR7 agonist increases responses of hepatitis $B$ virus-specific $T$ cells and natural killer cells in patients with chronic hepatitis B treated with nucleos(T)ide analogues. Gastroenterology 154: 1764-1777.e7, 2018

22. Agarwal K, Ahn SH, Elkhashab M, Lau AH, Gaggar A, Bulusu A, Tian X, Cathcart AL, Woo J, Subramanian GM, et al: Safety and efficacy of vesatolimod (GS-9620) in patients with chronic hepatitis B who are not currently on antiviral treatment. J Viral Hepat 25: 1331-1340, 2018.

23. Offersen R, Nissen SK, Rasmussen TA, Østergaard L, Denton PW, Søgaard OS and Tolstrup M: A novel toll-like receptor 9 agonist, MGN1703, enhances HIV-1 transcription and NK cell-mediated inhibition of HIV-1-infected autologous $\mathrm{CD}^{+} \mathrm{T}$ cells. J Virol 90: 4441-4453, 2016

24. Tsai A, Irrinki A, Kaur J, Cihlar T, Kukolj G, Sloan DD and Murry JP: Toll-like receptor 7 agonist GS-9620 induces HIV expression and HIV-specific immunity in cells from HIV-infected individuals on suppressive antiretroviral therapy. J Virol 91: e02166-16, 2017.

25. Sloan DD, Irrinki A, Tsai A, Kaur J, Lalezari J, Murry J and Cihlar T: TLR7 agonist GS-9620 activates HIV-1 in PBMCs from HIV-infected patients on cART. 22nd Annu Conf Retrovir Opportunist Infect, Seattle, WA, abs. 417, February 23-26, 2015 https://www.croiconference.org/abstract/tlr7-agonist-gs-9620activates-hiv-1-pbmcs-hiv-infected-patients-cart/.

26. Ram RR, Duatschek P, Margot N, Abram M, Geleziunas R, Hesselgesser J and Callebaut C: Activation of HIV-specific CD8 ${ }^{+}$ T-cells from $\mathrm{HIV}^{+}$donors by vesatolimod. Antivir Ther: May 18, 2020 (Epub ahead of print). doi: 10.3851/IMP3359.

27. Lim SY, Osuna CE, Hraber PT, Hesselgesser J, Gerold JM, Barnes TL, Sanisetty S, Seaman MS, Lewis MG, Geleziunas R, et al: TLR7 agonists induce transient viremia and reduce the viral reservoir in SIV-infected rhesus macaques on antiretroviral therapy. Sci Transl Med 10: eaao4521, 2018.

28. Borducchi EN, Liu J, Nkolola JP, Cadena AM, Yu WH, Fischinger S, Broge T, Abbink P, Mercado NB, Chandrashekar A, et al: Antibody and TLR7 agonist delay viral rebound in SHIV-infected monkeys. Nature 563: 360-364, 2018.

29. Riddler S, Para M, Benson C, Mills A, Ramgopal M, Dejesus E, Brinson C, Cyktor J, Mellors J, Guo S, et al: Vesatolimod (GS-9620) is safe and pharmacodynamically active in HIV infected individuals. 10th International AIDS Society Conference on HIV Science (IAS 2019), Mexico City. abstract WEAA0304, 2019. https://www.natap.org/2019/IAS/IAS 47.htm.

30. Li SY, Li H, Xiong YL, Liu F, Peng ML, Z̆hang DZ, Ren H and $\mathrm{Hu}$ P: Peginterferon is preferable to entecavir for prevention of unfavourable events in patients with $\mathrm{HBeAg}$-positive chronic hepatitis B: A five-year observational cohort study. J Viral Hepat 24 (Suppl 1): 12-20, 2017.
31. Azzoni L, Foulkes AS, Papasavvas E, Mexas AM, Lynn KM, Mounzer K, Tebas P, Jacobson JM, Frank I, Busch MP, et al: Pegylated Interferon alfa-2a monotherapy results in suppression of HIV type 1 replication and decreased cell-associated HIV DNA integration. J Infect Dis 207: 213-222, 2013.

32. Sun H, Buzon MJ, Shaw A, Berg RK, Yu XG, Ferrando-Martinez S, Leal M, Ruiz-Mateos E and Lichterfeld M: Hepatitis C therapy with interferon- $\alpha$ and ribavirin reduces CD4 T-cell-associated HIV-1 DNA in HIV-1/hepatitis C virus-coinfected patients. J Infect Dis 209: 1315-1320, 2014.

33. Jiao YM, Weng WJ, Gao QS, Zhu WJ, Cai WP, Li LH, Li HJ, Gao YQ and Wu H: Hepatitis C therapy with interferon- $\alpha$ and ribavirin reduces the CD4 cell count and the total,2LTR circular and integrated HIV-1 DNA in HIV/HCV co-infected patients. Antiviral Res 118: 118-122, 2015.

34. Dianzani F, Rozera G, Abbate I, D'Offizi G, Abdeddaim A, Vlassi C,Antonucci G, Narciso P, Martini F and Capobianchi MR: Interferon may prevent HIV viral rebound after HAART interruption in HIV patients. J Interferon Cytokine Res 28: 1-3, 2008.

35. Asmuth DM, Murphy RL, Rosenkranz SL, Lertora JJ, Kottilil S Cramer Y, Chan ES, Schooley RT, Rinaldo CR, Thielman N, et al: Safety, tolerability, and mechanisms of antiretroviral activity of pegylated interferon Alfa-2a in HIV-1-monoinfected participants: A phase II clinical trial. J Infect Dis 201: 1686-1696, 2010.

36. Tavel JA, Huang CY, Shen J, Metcalf JA, Dewar R, Shah A, Vasudevachari MB, Follmann DA, Herpin B, Davey RT, et al: Interferon-alpha produces significant decreases in HIV load. J Interferon Cytokine Res 30: 461-464, 2010.

37. Frissen PH, de WolfF, Reiss P,Bakker PJ, Veenhof CH,DannerSA, Goudsmit J and Lange JM: High-dose interferon-alpha2a exerts potent activity against human immunodeficiency virus type 1 not associated with antitumor activity in subjects with Kaposi's sarcoma. J Infect Dis 176: 811-814, 1997.

38. Haas DW, Lavelle J, Nadler JP, Greenberg SB, Frame P, Mustafa N, St Clair M, McKinnis R, Dix L, Elkins M and Rooney J: A randomized trial of interferon alpha therapy for HIV type 1 infection. AIDS Res Hum Retroviruses 16: 183-190, 2000.

39. Hua S, Vigano S, Tse S, Zhengyu O, Harrington S, Negron J, Garcia-Broncano P, Marchetti G, Genebat M, Leal M, et al: Pegylated interferon- $\alpha$-induced natural killer cell activation is associated with human immunodeficiency virus-1 DNA decline in antiretroviral therapy-treated HIV-1/hepatitis C virus-coinfected patients. Clin Infect Dis 66: 1910-1917, 2018.

40. Montes ML, Schapiro J, Pérez-Valero I, García-Bujalance S and Arribas JR: Long-term control of HIV replication with dolutegravir and pegylated interferon alpha-2a in an HIV-infected patient with sixtuple-class resistance. AIDS 28: 932-934, 2014.

41. Sandler NG, Bosinger SE, Estes JD, Zhu RT, Tharp GK, Boritz E, Levin D, Wijeyesinghe S, Makamdop KN, del Prete GQ, et al: Type I interferon responses in rhesus macaques prevent SIV infection and slow disease progression. Nature 511: 601-605, 2014.

42. Hardy GA, Sieg S, Rodriguez B, Anthony D, Asaad R, Jiang W, Mudd J, Schacker T, Funderburg NT, Pilch-Cooper HA, et al: Interferon- $\alpha$ is the primary plasma type-I IFN in HIV-1 infection and correlates with immune activation and disease markers. PLoS One 8: e56527, 2013.

43. Fraietta JA, Mueller YM, Yang G, Boesteanu AC, Gracias DT, Do DH, Hope JL, Kathuria N, McGettigan SE, Lewis MG, et al: Type I interferon upregulates Bak and contributes to T cell loss during human immunodeficiency virus (HIV) infection. PLoS Pathog 9: e1003658, 2013.

44. Cheng L, Ma J, Li J, Li D, Li G, Li F, Zhang Q, Yu H, Yasui F, Ye C, et al: Blocking type I interferon signaling enhances T cell recovery and reduces HIV-1 reservoirs. J Clin Invest 127: 269-279, 2017.

45. D'Offizi G, Gioia C, Corpolongo A, Martini F, Paganelli R, Volpi I, Sacchi A, Tozzi V, Narciso P and Poccia F: An IL-15 dependent CD8 T cell response to selected HIV epitopes is related to viral control in early-treated HIV-infected subjects. Int. J Immunopathol Pharmacol 20: 473-485, 2007.

46. Han W, Ni Q, Liu K, Yao Y, Zhao D, Liu X and Chen Y: Decreased CD122 on CD56dim NK associated with its impairment in asymptomatic chronic HBV carriers with high levels of HBV DNA, HBsAg and HBeAg. Life Sci 195: 53-60, 2018.

47. Garrido C,Abad-Fernandez M,Tuyishime M,Pollara JJ,FerrariG, Soriano-Sarabia N and Margolis DM: Interleukin-15-stimulated natural killer cells clear HIV-1-infected cells following latency reversal ex vivo. J Virol 92: e00235, 2018. 
48. Jones RB, Mueller S, O'Connor R, Rimpel K, Sloan DD, Karel D, Wong HC, Jeng EK, Thomas AS, Whitney JB, et al: A subset of latency-reversing agents expose $\mathrm{HIV}$-infected resting $\mathrm{CD}^{+}$ T-cells to recognition by cytotoxic T-lymphocytes. PLoS Pathog 12: e1005545, 2016.

49. McBrien JB, Mavigner M, Franchitti L, Smith SA, White E, Tharp GK, Walum H, Busman-Sahay K, Aguilera-Sandoval CR, Thayer WO, et al: Robust and persistent reactivation of SIV and HIV by N-803 and depletion of CD8 ${ }^{+}$cells. Nature 578: 154-159, 2020.

50. Ellis-Connell AL, Balgeman AJ,Zarbock KR, Barry G, Weiler A, Egan JO, Jeng EK, Friedrich T, Miller JS, Haase AT, et al: ALT-803 transiently reduces simian immunodeficiency virus replication in the absence of antiretroviral treatment. J Virol 92 e01748-17, 2018

51. Walter J, Ghosh MK, Kuhn L, Semrau K, Sinkala M, Kankasa C, Thea DM and Aldrovandi GM: High concentrations of interleukin 15 in breast milk are associated with protection against postnatal HIV transmission. J Infect Dis 200: 1498-1502, 2009.

52. Oh S, Berzofsky JA, Burke DS, Waldmann TA and Perera LP: Coadministration of HIV vaccine vectors with vaccinia viruses expressing IL-15 but not IL-2 induces long-lasting cellular immunity. Proc Natl Acad Sci USA 100: 3392-3397, 2003.

53. Mueller YM, Do DH, Altork SR, Artlett CM, Gracely EJ, Katsetos CD, Legido A, Villinger F, Altman JD, Brown CR, et al IL-15 treatment during acute simian immunodeficiency virus (SIV) infection increases viral set point and accelerates disease progression despite the induction of stronger SIV-specific CD8 ${ }^{+}$ T cell responses. J Immunol 180: 350-360, 2008.

54. Hryniewicz A, Price DA, Moniuszko M, Boasso A Edghill-Spano Y, West SM, Venzon D, Vaccari M, Tsai WP, Tryniszewska E, et al: Interleukin-15 but not interleukin-7 abrogates vaccine-induced decrease in virus level in simian immunodeficiency virus mac251-infected macaques. J Immunol 178: 3492-3504, 2007.

55. Swaminathan S, Qiu J, Rupert AW, Hu Z, Higgins J, Dewar RL, Stevens R, Rehm CA, Metcalf JA, Sherman BT, et al: Interleukin-15 (IL-15) strongly correlates with increasing HIV-1 viremia and markers of inflammation. PLoS One 11: e0167091, 2016.

56. Agostini C, Trentin L, Sancetta R, Facco M, Tassinari C Cerutti A, Bortolin M, Milani A, Siviero M, Zambello R and Semenzato G: Interleukin-15 triggers activation and growth of the CD8 T-cell pool in extravascular tissues of patients with acquired immunodeficiency syndrome. Blood 90: 1115-1123, 1997.

57. Yin W, Xu L, Sun R, Wei H and Tian Z: Interleukin-15 suppresses hepatitis B virus replication via IFN- $\beta$ production in a C57BL/6 mouse model. Liver Int 32: 1306-1314, 2012.

58. Di Scala M, Otano I, Gil-Fariña I, Vanrell L, Hommel M, Olagüe C, Vales A, Galarraga M, Guembe L, Ortiz de Solorzano C, et al: Complementary effects of interleukin-15 and alpha interferon induce immunity in hepatitis B virus transgenic mice. J Virol 90: 8563-8574, 2016

59. Ichimura $\mathrm{H}$ and Levy JA: Polymerase substrate depletion: A novel strategy for inhibiting the replication of the human immunodeficiency virus. Virology 211: 554-560, 1995.

60. Margolis D, Heredia A, Gaywee J, Oldach D, Drusano G and Redfield R: Abacavir and mycophenolic acid, an inhibitor of inosine monophosphate dehydrogenase, have profound and synergistic anti-HIV activity. J Acquir Immune Defic Syndr 21: 362-370, 1999.

61. Cohn RG, Mirkovich A, Dunlap B, Burton P, Chiu SH, Eugui E and Caulfield JP: Mycophenolic acid increases apoptosis, lysosomes and lipid droplets in human lymphoid and monocytic cell lines. Transplantation 68: 411-418, 1999.

62. Allison AC and Eugui EM: Mechanisms of action of mycophenolate mofetil in preventing acute and chronic allograft rejection Transplantation 80 (Suppl 2): S181-S190, 2005.

63. García F, Plana M, Arnedo M, Brunet M, Castro P, Gil C, Vidal E, Millán O, López A, Martorell J, et al: Effect of mycophenolate mofetil on immune response and plasma and lymphatic tissue viral load during and after interruption of highly active antiretroviral therapy for patients with chronic HIV infection: A randomized pilot study. J Acquir Immune Defic Syndr 36: 823-830, 2004

64. Ui H, Asanuma S, Chiba H, Takahashi A, Yamaguchi Y, Masuma R, Omura S and Tanaka H: Mycophenolic acid inhibits syncytium formation accompanied by reduction of gp120 expression. J Antibiot (Tokyo) 58: 514-518, 2005.
65. Margolis DM, Mukherjee AL, Fletcher CV, Hogg E, Ogata-Arakaki D, Petersen T, Rusin D, Martinez A and Mellors JW: The use of beta-D-2,6-diaminopurine dioxolane with or without mycophenolate mofetil in drug-resistant HIV infection. AIDS 21: 2025-2032, 2007.

66. Kaur R, Klichko V and Margolis D: Ex vivo modeling of the effects of mycophenolic acid on HIV infection: considerations for antiviral therapy. AIDS Res. Hum Retroviruses 21: 116-124, 2005.

67. Borroto-Esoda K, Myrick F, Feng J, Jeffrey J and Furman P In vitro combination of amdoxovir and the inosine monophosphate dehydrogenase inhibitors mycophenolic acid and ribavirin demonstrates potent activity against wild-type and drug-resistant variants of human immunodeficiency virus type 1 . Antimicrob Agents Chemother 48: 4387-4394, 2004.

68. Coull JJ, Turner D, Melby T, Betts MR, Lanier R and Margolis DM: A pilot study of the use of mycophenolate mofetil as a component of therapy for multidrug-resistant HIV-1 infection. J Acquir Immune Defic Syndr 26: 423-434, 2001

69. Chapuis AG, Paolo Rizzardi G, D'Agostino C, Attinger A, Knabenhans C, Fleury S, Acha-Orbea H and Pantaleo G: Effects of mycophenolic acid on human immunodeficiency virus infection in vitro and in vivo. Nat Med 6: 762-768, 2000.

70. Jurriaans S, Sankatsing SU, Prins JM, Schuitemaker H, Lange J, Van Der Kuyl AC and Cornelissen M: HIV-1 seroreversion in an HIV-1-seropositive patient treated during acute infection with highly active antiretroviral therapy and mycophenolate mofetil. AIDS 18: 1607-1608, 2004.

71. Heredia A, Margolis D, Oldach D, Hazen R, Le N and Redfield R: Abacavir in combination with the inosine monophosphate dehydrogenase (IMPDH)-inhibitor mycophenolic acid is active against multidrug-resistant HIV-1. J Acquir Immune Defic Syndr 22: 406-407, 1999

72. Hossain MM, Coull JJ, Drusano GL and Margolis DM: Dose proportional inhibition of HIV-1 replication by mycophenolic acid and synergistic inhibition in combination with abacavir, didanosine, and tenofovir. Antiviral Res 55: 41-52, 2002.

73. Margolis DM, Kewn S, Coull JJ, Ylisastigui L, Turner D, Wise H, Hossain MM, Lanier ER, Shaw LM and Back D: The addition of mycophenolate mofetil to antiretroviral therapy including abacavir is associated with depletion of intracellular deoxyguanosine triphosphate and a decrease in plasma HIV-1 RNA. J Acquir Immune Defic Syndr 31: 45-49, 2002.

74. Gong ZJ, De Meyer S, Clarysse C, Verslype C, Neyts J, De Clercq E and Yap SH: Mycophenolic acid, an immunosuppressive agent, inhibits HBV replication in vitro. J Viral Hepat 6: 229-236, 1999 .

75. Lau SC, Tse KC, Lai WM and Chiu MC: Use of prophylactic lamivudine and mycophenolate mofetil in renal transplant recipients with chronic hepatitis B infection. Pediatr Transplant 7: 376-380, 2003.

76. Wang J, Wang B, Huang S, Song Z, Wu J, Zhang E, Zhu Z, Zhu B, Yin Y, Lin Y, et al: Immunosuppressive drugs modulate the replication of hepatitis B virus (HBV) in a hydrodynamic injection mouse model. PLoS One 9: e85832, 2014

77. Wu J, Xie HY, Jiang GP, Xu X and Zheng SS: The effect of mycophenolate acid on hepatitis B virus replication in vitro. Hepatobiliary Pancreat Dis Int 2: 410-413, 2003.

78. Ying C, De Clercq E and Neyts J: Ribavirin and mycophenolic acid potentiate the activity of guanine- and diaminopurine-based nucleoside analogues against hepatitis B virus. Antiviral Res 48: $117-124,2000$

79. Ying C, Colonno R, De Clercq E and Neyts J: Ribavirin and mycophenolic acid markedly potentiate the anti-hepatitis $B$ virus activity of entecavir. Antiviral Res 73: 192-196, 2007.

80. Ben-Ari Z, Zemel R and Tur-Kaspa R: The addition of mycophenolate mofetil for suppressing hepatitis $\mathrm{B}$ virus replication in liver recipients who developed lamivudine resistance-no beneficial effect. Transplantation 71: 154-156, 2001.

81. Sayarlioglu H, Erkoc R, Dogan E, Sayarlioglu M and Topal C: Mycophenolate mofetil use in hepatitis B associated-membranous and membranoproliferative glomerulonephritis induces viral replication. Ann Pharmacother 39: 573, 2005.

82. Dong S, Geng L, Shen MD and Zheng SS: Natural killer cell activating receptor NKG2D is involved in the immunosuppressive effects of mycophenolate mofetil and hepatitis B virus infection. Am J Med Sci 349: 432-437, 2015.

83. Pan Q, van Vuuren AJ, van der Laan LJ, Peppelenbosch MP and Janssen HL: Antiviral or proviral action of mycophenolic acid in hepatitis B infection? Hepatology 56: 1586-1587, 2012. 
84. Hoppe-Seyler K, Sauer P, Lohrey C and Hoppe-Seyler F: The inhibitors of nucleotide biosynthesis leflunomide, FK778, and mycophenolic acid activate hepatitis B virus replication in vitro. Hepatology 56: 9-16, 2012.

85. Zwerner J and Fiorentino D: Mycophenolate mofetil. Dermatol Ther 20: 229-238, 2007.

86. Wang XF, Lei Y, Chen M, Chen CB, Ren H and Shi TD: PD-1/PDL1 and CD28/CD80 pathways modulate natural killer $\mathrm{T}$ cell function to inhibit hepatitis B virus replication. J Viral Hepat 20 (Suppl 1): S27-S39, 2013.

87. Féray C and López-Labrador FX: Is PD-1 blockade a potential therapy for HBV? JHEP Rep 1: 142-144, 2019.

88. Banga R, Procopio FA, Noto A, Pollakis G, Cavassini M, Ohmiti K, Corpataux JM, de Leval L, Pantaleo G and Perreau M: PD-1(+) and follicular helper T cells are responsible for persistent HIV-1 transcription in treated aviremic individuals. Nat Med 22: 754-761, 2016

89. Evans VA, van der Sluis RM, Solomon A, Dantanarayana A, McNeil C, Garsia R, Palmer S, Fromentin R, Chomont N, Sékaly RP, et al: Programmed cell death-1 contributes to the establishment and maintenance of HIV-1 latency. AIDS 32: 1491-1497, 2018.

90. Thibult ML, Mamessier E, Gertner-Dardenne J, Pastor S, Just-Landi S, Xerri L, Chetaille B and Olive D: PD-1 is a nove regulator of human B-cell activation. Int Immunol 25: 129-137, 2013.

91. Cubas RA, Mudd JC, Savoye AL, Perreau M, van Grevenynghe J, Metcalf T, Connick E, Meditz A, Freeman GJ, Abesada-Terk G $\mathrm{Jr}$, et al: Inadequate $\mathrm{T}$ follicular cell help impairs B cell immunity during HIV infection. Nat Med 19: 494-499, 2013.

92. Velu V, Titanji K, Zhu B, Husain S, Pladevega A, Lai L, Vanderford TH, Chennareddi L, Silvestri G, Freeman GJ, et al: Enhancing SIV-specific immunity in vivo by PD-1 blockade. Nature 458: 206-210, 2009.

93. Dyavar Shetty R, Velu V, Titanji K, Bosinger SE, Freeman GJ Silvestri G and Amara RR: PD-1 blockade during chronic SIV infection reduces hyperimmune activation and microbial translocation in rhesus macaques. J Clin Invest 122: 1712-1716, 2012

94. Gane E, Verdon DJ, Brooks AE, Gaggar A, Nguyen AH, Subramanian GM, Schwabe C and Dunbar PR: Anti-PD-1 blockade with nivolumab with and without therapeutic vaccination for virally suppressed chronic hepatitis B: A pilot study J Hepatol 71: 900-907, 2019.

95. Liu J, Zhang E, Ma Z, Wu W, Kosinska A, Zhang X, Möller I, Seiz P, Glebe D, Wang B, et al: Enhancing virus-specific immunity in vivo by combining therapeutic vaccination and PD-L1 blockade in chronic hepadnaviral infection. PLoS Pathog 10: e1003856, 2014

96. Fromentin R, DaFonseca S, Costiniuk CT, El-Far M, Procopio FA, Hecht FM, Hoh R, Deeks SG, Hazuda DJ, Lewin SR, et al: PD-1 blockade potentiates HIV latency reversal ex vivo in $\mathrm{CD}^{+} \mathrm{T}$ cells from ART-suppressed individuals. Nat Commun 10: 814, 2019.

97. Knolle PA and Thimme R: Hepatic immune regulation and its involvement in viral hepatitis infection. Gastroenterology 146 1193-1207, 2014.

98. Lake AC: Hepatitis B reactivation in a long-term nonprogressor due to nivolumab therapy. AIDS 31: 2115-2118, 2017.

99. Burova E, Hermann A, Waite J, Potocky T, Lai V, Hong S, Liu M, Allbritton $\mathrm{O}$, Woodruff $\mathrm{A}, \mathrm{Wu} \mathrm{Q}$, et al: Characterization of the anti-PD-1 antibody REGN2810 and its antitumor activity in human PD-1 knock-in mice. Mol Cancer Ther 16: 861-870, 2017.

100. Clinicaltrials.gov: Safety and Immunotherapeutic Activity of an Anti-PD-1 Antibody (Cemiplimab) in Participants With HIV-1 on Suppressive cART: A Phase I/II, Double-blind, Placebo-controlled, Ascending Multiple Dose Study. https://clinicaltrials.gov/ct2/show/NCT0 3787095 ?term $=$ NCT03787095\&draw $=1 \&$ rank $=1$. Accessed, September 9, 2020.

101. Clinicaltrials.gov: Safety and Immunotherapeutic Activity of Cemiplimab in Participants With HBV on Suppressive Antiviral Therapy: A Phase I/II Ascending Multiple Dose Study. https://clinicaltrials.gov/ct2/show/NCT04046107?term=NCT04 046107\&draw=1\&rank=1. Accessed, April 13, 2020.

102. Uldrick TS, Gonçalves PH, Abdul-Hay M, Claeys AJ, Emu B, Ernstoff MS, Fling SP, Fong L, Kaiser JC, Lacroix AM, et al: Assessment of the safety of pembrolizumab in patients with HIV and advanced cancer-a phase 1 study. JAMA Oncol 5: 1332-1339, 2019.
103. Wen X, Wang Y, Ding Y, Li D, Li J, Guo Y, Peng R, Zhao J, Zhang $X$ and Zhang XS: Safety of immune checkpoint inhibitors in Chinese patients with melanoma. Melanoma Res 26 284-289, 2016

104. Pandey A, Ezemenari S, Liaukovich M, Richard I and Boris A: A rare case of pembrolizumab-induced reactivation of hepatitis B. Case Rep Oncol Med 2018: 5985131, 2018.

105. Clinicaltrials.gov: PD-1 Inhibition to Determine CNS Reservoir of HIV-Infection. https://clinicaltrials.gov/ct2/show/NCT03 239899? term $=$ NCT03239899\&draw $=2 \&$ rank $=1$. Accessed September 18, 2020.

106. Kothapalli A and Khattak MA: Safety and efficacy of anti-PD-1 therapy for metastatic melanoma and non-small-cell lung cancer in patients with viral hepatitis: A case series. Melanoma Res 28: $155-158,2018$

107. Zhang X, Zhou Y, Chen C, Fang W, Cai X, Zhang X, Zhao M, Zhang B, Jiang W, Lin Z, et al: Hepatitis B virus reactivation in cancer patients with positive Hepatitis B surface antigen undergoing PD-1 inhibition. J Immunother Cancer 7: 322, 2019.

108. Velu V, Shetty RD, Larsson M and Shankar EM: Role of PD-1 co-inhibitory pathway in HIV infection and potential therapeutic options. Retrovirology 12: 14, 2015.

109. Wykes MN and Lewin SR: Immune checkpoint blockade in infectious diseases. Nat Rev Immunol 18: 91-104, 2018

110. Goshu BA, Chen H, Moussa M, Cheng J and Catalfamo M: Combination rhIL-15 and anti-PD-L1 (Avelumab) enhances HIVGag-specific CD8 T cell function. J Infect Dis 222: 1540-1549, 2020.

111. Balzarini J, Holy A, Jindrich J, Naesens L, Snoeck R, Schols D and De Clercq E: Differential antiherpesvirus and antiretrovirus effects of the $(S)$ and $(R)$ enantiomers of acyclic nucleoside phosphonates: Potent and selective in vitro and in vivo antiretrovirus activities of (R)-9-(2-phosphonomethoxypropyl)-2,6-diaminopurine. Antimicrob Agents Chemother 37: 332-338, 1993.

112. Ray AS, Fordyce MW and Hitchcock MJ: Tenofovir alafenamide: A novel prodrug of tenofovir for the treatment of human immunodeficiency virus. Antiviral Res 125: 63-70, 2016.

113. Cory TJ, Midde NM, Rao P and Kumar S: Investigational reverse transcriptase inhibitors for the treatment of HIV. Expert Opin Investig Drugs 24: 1219-1228, 2015.

114. Hostetler KY: Alkoxyalkyl prodrugs of acyclic nucleoside phosphonates enhance oral antiviral activity and reduce toxicity: Current state of the art. Antiviral Res 82: A84-A98, 2009.

115. Lanier ER, Ptak RG, Lampert BM, Keilholz L, Hartman T, Buckheit RW Jr, Mankowski MK, Osterling MC, Almond MR and Painter GR: Development of hexadecyloxypropyl tenofovir (CMX157) for treatment of infection caused by wild-type and nucleoside/nucleotide-resistant HIV. Antimicrob Agents Chemother 54: 2901-2909, 2010.

116. Painter GR, Almond MR, Trost LC, Lampert BM, Neyts J, De Clercq E, Korba BE, Aldern KA, Beadle JR and Hostetler KY: Evaluation of hexadecyloxypropyl-9-R-[2-(Phosphonomethoxy) propyl]-adenine, CMX157, as a potential treatment for human immunodeficiency virus type 1 and hepatitis B virus infections. Antimicrob Agents Chemother 51: 3505-3509, 2007.

117. Shire NJ: Cure strategies for hepatitis B virus: The promise of immunotherapy. Clin Pharmacol Drug Dev 6: 186-194, 2017.

118. Tajiri K and Shimizu Y: New horizon for radical cure of chronic hepatitis B virus infection. World J Hepatol 8: 863-873, 2016.

119. Clinicaltrials.gov: A Randomized, Double-blind, Placebo-controlled, Single-dose, Dose-escalation Study of the Safety, Tolerability and Pharmacokinetics of CMX157 in Healthy Adult Volunteers. Available from: https://clinicaltrials. gov/ct $2 /$ show/NCT01080820?term $=$ NCT01080820\&draw $=2 \&$ rank=1. Accessed July 4, 2011.

120. Clinicaltrials.gov [updated September 13, 2017]. A Phase 2, Randomized, Open-label, Ascending, Sequential Dose Group, Multiple Dose Study of the Safety, Tolerability, Pharmacokinetics and Antiviral Activity of CMX157 in HBV-infected Subjects. https://clinicaltrials.gov/ct2/show/NCT02710604?term=NCT02 $710604 \&$ draw $=2 \&$ rank=1. Accessed September 13, 2017.

121. Clinicaltrials.gov: A Phase 1, Randomized, Partial-Blind, Placebo-controlled, Sequential Dose Group, Ascending, Multiple Dose Study of the Safety, Tolerability and Pharmacokinetics, With Food Effect, of CMX157 in Healthy Subjects. Available from: https://clinicaltrials.gov/ct2/show/NCT02585440?term= NCT02585440\&draw=2\&rank=1. Accessed February 2, 2017. 
122. Allam C: Wraltechwire: ContraVir terminates licensing agreement for Chimerix drug.https://www.wraltechwire.com/2019/04/05/contravirterminates-licensing-agreement-for-chimerix-drug/. Accessed April 5, 2019.

123. Gallay P, Chatterji U, Bobardt MD, Ure D, Trepanier D, Foster R and Ordonez C: Novel cyclophilin inhibitor CPI-431-32 shows broad spectrum antiviral action by blocking replication of $\mathrm{HCV}$, HBV, and HIV-1. J Hepatol 62 (Suppl 2): S677, 2015.

124. Trepanier DJ, Ure DR and Foster RT: In vitro phase I metabolism of CRV431, a novel oral drug candidate for chronic hepatitis B. Pharmaceutics 9: 51, 2017.

125. Hansson MJ, Moss SJ, Bobardt M, Chatterji U, Coates N, Garcia-Rivera JA, Elmér E, Kendrew S, Leyssen P, Neyts J, et al: Bioengineering and semisynthesis of an optimized cyclophilin inhibitor for treatment of chronic viral infection. Chem Biol 22: 285-292, 2015.

126. Phillips S, Chokshi S, Chatterji U, Riva A, Bobardt M, Williams R, Gallay P and Naoumov NV: Alisporivir inhibition of hepatocyte cyclophilins reduces HBV replication and hepatitis B surface antigen production. Gastroenterology 148: 403-414.e7, 2015

127. Gallay PA, Bobardt MD, Chatterji U, Trepanier DJ, Ure D, Ordonez $\mathrm{C}$ and Foster R: The novel cyclophilin inhibitor CPI-431-32 concurrently blocks HCV and HIV-1 infections via a similar mechanism of action. PLoS One 10: e0134707, 2015.

128. BIOSPACE: ContraVir's Cyclophilin Inhibitor CRV431 Potently Inhibits Essential Pathway In Hepatitis B. https://www.biospace. com/article/releases/contravir-s-cyclophilin-inhibitor-crv431-p otently-inhibits-essential-pathway-in-hepatitis-b-/. Accessed December 08, 2016.

129. Hardy A: BIOTUESDAYS: Hepion Pharmaceuticals' CEO Robert Foster discusses CRV431's potential in NASH. https://biotuesdays.com/2019/07/30/hepion-pharmaceuticals-ce o-robert-foster-discusses-crv431s-potential-in-nash/. Accessed July 30, 2019.
130. Gallay P, Ure D, Bobardt M, Chatterji U, Ou J, Trepanier D and Foster R: The cyclophilin inhibitor CRV431 inhibits liver HBV DNA and HBsAg in transgenic mice. PLoS One 14: e0217433, 2019.

131. Clinicaltrials.gov: A Randomized, Partially-blinded, Placebo-controlled, Ascending Sequential Dose Groups, Single Dose Study of the Safety, Tolerability and Pharmacokinetics of CRV431, Alone and In Combination With Tenofovir Disoproxil Fumarate in Healthy Subjects, With a Pilot Study of Multiple Ascending Sequential Doses in Healthy Volunteer Subjects. https://clinicaltrials.gov/ct2/show/NCT03596697?term=CRV43 $1 \&$ cond=HBV\&draw=2\&rank=1. Accessed June 30, 2020.

132. Kuo J, Bobardt M, Chatterji U, Mayo PR, Trepanier DJ, Foster RT, Gallay P and Ure DR: A pan-cyclophilin inhibitor, CRV431, decreases fibrosis and tumor development in chronic liver disease models. J Pharmacol Exp Ther 371: 231-241, 2019.

133. Wai CT, Chu CJ, Hussain M and Lok AS: HBV genotype $\mathrm{B}$ is associated with better response to interferon therapy in $\mathrm{HBeAg}(+)$ chronic hepatitis than genotype C. Hepatology 36: 1425-1430, 2002.

134. Papatheodoridis G, Dimou E and Papadimitropoulos V: Nucleoside analogues for chronic hepatitis B: Antiviral efficacy and viral resistance. Am J Gastroenterol 97: 1618-1628,2002.

(i) $($ This work is licensed under a Creative Common Attribution-NonCommercial-NoDerivatives 4.0 International (CC BY-NC-ND 4.0) License. 